\title{
Striving for Work-Life Balance at Entry Level Jobs: Challenges to Develop Professionalism in Bangladesh
}

\author{
Afdalin Bin Haque ${ }^{1 *}$, Aryana Anan Ahmed ${ }^{2}$ \\ ${ }^{1}$ Lecturer, Department of Management, American International University-Bangladesh, Dhaka, BANGLADESH \\ ${ }^{2}$ Lecturer, Department of Human Resource Management, Stamford University Bangladesh, Dhaka, BANGLADESH \\ *E-mail for correspondence: afdalinhaque@yahoo.com
}

Received: Apr 26, 2016

Accepted: May 16, 2016

\begin{abstract}
The rising issue regarding the decline in organizational commitment of employees is nowadays a primary concern of employers and also HR department of any organization. These issues are observedin the entry level jobsmore densely where the socialization process takes place and in such area the newcomers feel deprived of any kind and every kind of facility. A fresh graduate joining into the workforce faces new challenges every day and mostly the Work-Life balance issue which is related to his or her job satisfaction and ultimately commitment towards his organization. The aim of this study is to identify the factors, especially the thoughts of employees regarding their Work-Life balance in an entry level job. The study will also bridge the gap between the expectation and realities of employees' Work-Life balance and prescribing some corrections to the work structure.
\end{abstract}

Keywords: Work-Life Balance; Entry Level Job; Professionalism Development; Time Management; Stress; Job Satisfaction JEL Classification Code: J28; J29

\section{INTRODUCTION}

The term "Work-Life balance" refers to balance "work" such as professional career, ambition with "Life" such as health, family, pleasure and leisure, especially used for employees those who are expecting Work-Life balance in their life. This Work-Life balance issue arises due to the technological advancement as one of the reasons. Also, employers are keeping a connection with employees through electronic media such as mobile, email, etc. even though if the employee is at home. As a result, in a week employer sometimes communicate with them for different issues which de-motivate employees as because they are spending their weekend (Boswell and Julie, 2007). In Bangladesh staffs are not getting flexible working hour, as a result, they do not find workplace stimulating. Therefore, most of the employees are having a high level of stress, illness due to stress, family problem, violence, higher absenteeism and turnover, reduce productivity and job satisfaction (Hobson, et al., 2001).

The only key success factor the organizations' success nowdays is not the figures which are added to the organizations' bottom line. The organizations' are currently more focused and concerned about the wellbeing and satisfaction of the employees and WorkLife balance encompasses a major portion of job satisfaction. It is good to be true that the organizations' must be accountable for the employees' satisfaction nevertheless some responsibility also belongs to the employees these days.

\section{RATIONALE OF THE STUdY}

Work-life balance, in its broadest sense, is defined as a satisfactory level of involvement or "fit" between the multiple roles in a person's life (Hudson, 2005). There is no one accepted the definition of what constitutes a worklife balance practice, the term usually refers to one of the following: organizational support for dependent care, flexible work options, and family or personal leave (Estes \& Michael, 2005). Hence, these practices include flexible work hours (e.g., flextime, which permits workers to vary their start and finish times, provided a certain number of hours is worked; compressed work week, in which employees work a full week's worth of hours in four days and take the fifth off), working from home (telecommuting), sharing a full-time job between two employees (job sharing), family leave programs (e.g., parental leave, adoption leave, compassionate leave), onsite childcare, and financial and/or informational assistance with childcare and eldercare services (Kar \& Misra, 2013). Susi et al. (2011) state that, work-life balance policies can assist employees achieving a balance between their work and personal commitments those are right for them. Those guidelines need to get support from the workplace culture, which reflects the beliefs, values, and 
norms of the whole of the organization from the CEO to staff members. Other important factors in the success of work-life balance policies include proper communication of commitment to the policies to existing and future employees, raising awareness regarding guidelines, education of executives about the importance of policies, and training of managers on "how to" implement these policies. Inconsistent Work-Life balance creates a negative impact while developing professionalism and job insecurity discourages employees not to work with their utmost concentration. Bangladesh needs to change with time as the world is having Political, Economic, Social, Technological, Environmental and Legal changes. Bangladesh needs to cope up with the dynamic world, therefore, change in economic trends, globalization impact, competitive market, a huge supply of work, made the Work-Life balance situation more critical (Baral and Bhargava, 2011). Still there is some confusion, whether employees are claiming that they do not have Work-Life balance even though they are getting payment for overtime for excess work, or work is ruining their life because they are getting lots of work pressure from the employer (Eikhof, et al., 2007). An official task that is given in closing time as well as unpredictable tasks that are excluded from the employee job description also creates stress for the employee (Drew and Murtagh, 2005). To develop professionalism, there should be a positive balance between work and life which will increase the quality of life. At the same time, it will lead job satisfaction for the employees (Greenhaus et al., 2003). For further development of professionalism in Bangladesh it is very much vital to expel situations that restrict employees to connect to their respective jobs and organizations.

Based on the above discussion it mainly focuses on the imbalance between work and life. However, this imbalance can be minimized by providing monetary and or non-monetary motivations to employees. Hence, to cope with the dynamic working environment in Bangladesh, employees may not be able to get their desired working environment. In this current research report, I have presented how the employees of Bangladesh are striving for their Work-Life balance as well as the challenges that they are facing to develop professionalism. Additionally, especially new employees are facing this issue at their organization due to having a different job description or the duty assigned to them. This issue triggers Work-Life balance issue for those employees which ultimately lead for job dissatisfaction. Moreover, job dissatisfaction also leads fewer outcomes from the potential employees. As a result the expected amount of output cannot be gained from the employee who affects the organization negatively. Therefore, the objective of this study was to explore the reason behind imbalance Work-Life and different responsible criteria's for this imbalance Work-Life. Also, this study also focused on the employee motivation process to reduce the imbalance between work and life. This study will also provide further guidance to conduct more exploratory research to find out other related factors of work-life balance outlined with other demographic variables. The scope for further studies will develop.

\section{Statement of the Problem}

This research helped to explore the reason behind imbalance Work-Life and different responsible criteria for this imbalance Work-Life. It also focused on certain criteria such as working hours of employees, time spending with family, attitudes towards Work-Life balance, workload, stress management, job description, motivational aspects, etc. Also, it also focused on the employee motivation process to reduce the imbalance between work and life.

\section{OBJectives OF The Study}

On a broader sense, the projection of this research was to explore different phase that triggers the imbalance between work and life. Additionally, the specific objectives of this study were to:

- Explore some key variables that may trigger imbalanced work and life,

- How employees are becoming stressed at workplace,

- Exploration of their working hours, workload, payment for overtime,

- Assessment of their job description and to explore whether they are getting any unwanted jobs,

- Time management - work, time spent with family.

\section{LITERATURE REVIEW}

This work-life balance became a crucial issue for Bangladeshi context; therefore, this needs to be solved, through resolving this issue the outcome of employees may increase than their current problems. Three components of work-life balance those are time balance (equal time devoted to work and family), involvement balance (equal involvement in work and family), and satisfaction balance (equal satisfaction with work and family). For individuals who invested substantial time in their combined work and family roles, those who spent more time on family than work experienced a higher quality of life than balanced individuals who, in turn, experienced a higher quality of life than those who spent more time on work than family (Greenhaus et al., 2003). Work-life balance focuses on few criteria, which are, the notion of equality, or near-equality, between experiences in the work role and experiences in the family role imply similarly higher levels of satisfaction, functioning, health, or effectiveness across multiple roles (Clark, et al., 2000).

Moreover, work-life balance mainly based on two components of equality: inputs and outcomes. The inputs are the personal resources (Kirchmeyer, 2000). To be balanced is to approach each role-work and lifewith an approximately equal level of attention, time, 
involvement, or commitment (Greenhaus et al., 2003). Positive balance suggests an equally high level of attention, time, involvement, or commitment, whereas negative balance refers to an equally low level of attention, time, involvement, or commitment. These inputs reflect an individual's level of role engagementin terms of time devoted to each role or psychological involvement in each role. It is difficult to imagine a balanced individual who is substantially more or less engaged in the work role than the family role. Greenhaus, Collins \& Shaw (2003) emphasizes that, there are some other unaddressed factors which are important in order to know more about work-life balance, those factors are:

- Time balance: an equal amount of time devoted to work and family roles.

- Involvement balance: an equal level of psychological involvement in work and family roles.

- Satisfaction balance: an equal level of satisfaction with work and family roles.

Each factor of work-life balance can represent positive balance or negative balance depending on whether the levels of time, involvement, or satisfaction are equally high or equally low. Moreover, a balanced involvement in work and life roles may also reduce continuing work and family conflict (Greenhaus et al., 2003). Because balanced individuals are fully engaged in both roles, they do not allow "situational urgencies" to hinder role performance chronically (Marks \& MacDermid, 1996). Greenhaus et al. (2003) further argues, however, the relation between satisfaction balance and quality of life is likely to depend on the total level of satisfaction across work and family roles. Under conditions of high total satisfaction, there is more satisfaction to distribute across work and family roles. Therefore, imbalance can produce sizeable differences between work satisfaction and family satisfaction, a high level of stress, and therefore a low quality of life. Under conditions of low total satisfaction, where there is not much satisfaction to distribute across roles, imbalance produces minor differences between work satisfaction and family satisfaction, generates little stress, and has little or no effect on quality of life (Greenhaus et al., 2003). On the other hand, accumulated some extended research findings based on U.S. employees and tried to assess the outcomes of not having a proper work-life balance in organizations (Newaz\& Zaman, 2012). The findings include - increased levels of stress and stress-related illness, higher rates of family strife, violence and divorce, higher rates of absenteeism and turnover, reduced productivity and job satisfaction (Hobson, et al., 2001).

Dhas \& Karthikeyan (2015) illustrated their findings saying that, the meaning of work/life balance has chameleon characteristics. It means different things to different groups, and the meaning often depends on the context of the conversation and the speaker's viewpoint.
The following are working definitions of terms used regarding work/life balance; some definitions overlap and some are continuing to evolve.

- Work/family: a term more frequently used in the past than today. The current trend is to use titles that include the phrase work/life, giving a broader work/life connotation or labeling referring to specific areas of support (e.g., quality of life, flexible work options, life balance, etc.)

- Work/family conflict: the push and pull between work and family responsibilities.

- Work/life balance from the employee viewpoint: the dilemma of managing work obligations and personal/family duties.

- Work/life balance from the employer viewpoint: the challenge of creating a supportive company culture where employees can focus on their jobs while at work.

- Family-friendly benefits: benefits that offer employees the latitude to address their personal and family commitments, while at the same time not compromising their professional responsibilities.

- Work/life programs: programs (often financial or time-related) established by an employer that offer employees options to address job and personal responsibilities.

- Work/life initiatives: policies and procedures established by an organization with the goal to enable employees to get their jobs done and at the same time provide flexibility to handle personal/family concerns.

- Work/family culture: the extent to which an organization's culture acknowledges and respects the family responsibilities and obligations of its employees and encourages management and employees to work together to meet their personal and work needs.

Newaz \& Zaman (2012) advocate that, proper work-life balance can make them more committed which will work as an intrinsic motivation. Moreover, it also helps to build a positive psychological contract and better job satisfaction for the employees which will ultimately assist to increase the retention rate. In apparent recognition of this finding, managers should establish trust in employees, build high standard of excellence, and where necessary, delegate authority in order to enhance employees' intrinsic motivation. Which certify the necessity of a proper work-life balance? Furthermore, the future development of employees' to some extent depends on their self-motivation.

However, the existence of work-life balance in itself does not create difficulties and offence within organizations; rather, in situations where there is already excessive workloads, under-staffing, and last minute, unpredicted tasks, the existence of work-life balance is likely to 
exacerbate the situations (Drew \& Murtagh, 2005). Nonetheless, there are quite a few research studies on work-family conflict in developing countries like Bangladesh and one of the reasons could be the lack of awareness of this issue as well as the lack of awareness of equal employment opportunity act. (Baral \& Bhargava, 2011). According to Baral \& Bhargava (2011), a study on work-family enrichment in India would be prudent because of its cultural roots, where people consider work as a source of income and social status. At the same time, for people in India, the family is a social institution that provides not only emotional support but also stands with them in times of crisis (Baral \& Bhargava, 2011). The same scenario is very much pertinent in Bangladesh (Newaz et al., 2012).

Work/life programs have the potential to significantly improve employee morale, reduce absenteeism, and retain organizational knowledge, particularly during difficult economic times. In today's global marketplace, as companies aim to reduce costs, it falls to the human resource professional to understand the critical issues of work/life balance and champion work/life programs (Dhas \& Karthikeyan 2015). Be it employees whose family members and/or friends are called to serve their country, single mothers who are trying to raise their children and make a living, Generation $X$ and $Y$ employees who value their personal time, couples struggling to manage dual-career marriages, or companies losing critical knowledge when employees leave for other opportunities, work/life programs offer a win-win situation for employers and employees (Dhas \& Karthikeyan 2015). And the statement commends the utility of work-life balance programs and its increasing necessity for organizations and employees as well.

\section{Methodology}

In order to prepare this research a combination of both theoretical and conceptual framework was used. There are different theories regarding Work-Life balance in human resource management from which some concepts were developed to conduct this research.

I designed the survey questionnaire with a combination of open-ended and closed-ended questions to conduct this study. Also, this study was conducted in two major areas of Dhaka city where all the well-known private organizations are situated.

I used a quantitative method for conducting this study. This study was focused on certain criteria such as general, daily and weekly working hours, time spending with family, job satisfaction level, attitudes towards Work-Life balance, workload, stress management, job description, motivational aspects, etc. Finally, openended question was developed for their suggestion along with their personal comments regarding their organization which I consider as a qualitative method.
Therefore, quantitative and qualitative methods were used for this report. Additionally, the questionnaire was designed in such a way that, Respondents can have their privacy and security as because, I omitted the name of the responder, organization name was not mandatory. The reason for designing such questionnaire was to keep their official position safe and sound. Additionally, being married and having children also triggers work-life balance issue since during this time employees have more responsibilities towards their family.

All the collected data was compiled through Excel for statistical treatment. Furthermore analysis was done through the measure of central tendency. Moreover, Mean and Percentage, standard deviation, $\mathrm{CV} \%$ analysis was used in order to compare all the data based on the feedback of Respondents. Some data were reflected through tables and pie charts.

Sample size (n) for the study was 50 which was a combination of males and female employees working in local and multinational organizations in Bangladesh. Samples were collected randomly from the proposed work location. Although it was a medium scale survey, but stratified random sampling was chosen as a survey sampling method in order to get accurate information without biasness. Moreover, to make the research result more accurate and systematic, some additional subsets were added like percentage of males and females, types of company which reduced the sampling error.

The sample management was done through Microsoft Excel 2010 application program. Initially, all the information was collected through questionnaire and later on it was recorded on the excel software by categorizing criteria's based on the objectives. After inputting all the information by eliminating errors, those were transferred to another excel tab to make them meaningful and preparing that information for interpretation through tabular and graphical method.

To analyze data, a descriptive statistical analysis was done. Some information was analyzed through mean, standard deviation, variance and percentage analysis specially their working hours. However variables were analyzed through standard deviation. Additionally, fraction analysis was done in order to know their satisfaction rate and other similar variables.

\section{Data Analysis and Discussion}

The following table will give a picture of the sample used for the research. And based on contextual approach the samples were randomly selected and also the distribution. $72 \%$ of the Respondents were male, and the remaining $28 \%$ were females working at entry level in different local and multinational service oriented organizations in Bangladesh. 
Table 1: Sample distributions, $n=50$ by gender and relationship status

\begin{tabular}{|l|l|l|l|l|l|}
\hline \multirow{2}{*}{ Sl. } & \multicolumn{2}{|l|}{ Employee Pattern } & \multirow{2}{*}{ Sl. } & Employee Pattern \\
& M/F* & S/M* & & M/F & S/M \\
\hline 1 & Male & Single & 26 & Male & Married \\
\hline 2 & Male & Single & 27 & Male & Married \\
\hline 3 & Male & Single & 28 & Male & Single \\
\hline 4 & Male & Single & 29 & Male & Single \\
\hline 5 & Male & Single & 30 & Male & Single \\
\hline 6 & Male & Single & 31 & Male & Single \\
\hline 7 & Male & Single & 32 & Male & Single \\
\hline 8 & Male & Single & 33 & Male & Single \\
\hline 9 & Male & Married & 34 & Male & Single \\
\hline 10 & Male & Single & 35 & Male & Married \\
\hline 11 & Male & Single & 36 & Male & Married \\
\hline 12 & Male & Single & 37 & Female & Married \\
\hline 13 & Male & Single & 38 & Female & Single \\
\hline 14 & Male & Single & 39 & Female & Married \\
\hline 15 & Male & Single & 40 & Female & Married \\
\hline 16 & Male & Single & 41 & Female & Married \\
\hline 17 & Male & Single & 42 & Female & Single \\
\hline 18 & Male & Single & 43 & Female & Single \\
\hline 19 & Male & Single & 44 & Female & Married \\
\hline 20 & Male & Single & 45 & Female & Married \\
\hline 21 & Male & Married & 46 & Female & Married \\
\hline 22 & Male & Married & 47 & Female & Married \\
\hline 23 & Male & Married & 48 & Female & Married \\
\hline 24 & Male & Single & 49 & Female & Married \\
\hline 25 & Male & Single & 50 & Female & Single \\
\hline
\end{tabular}

${ }^{*} \mathrm{M} / \mathrm{F}$ : Male or Female

** S/M: Single or Married

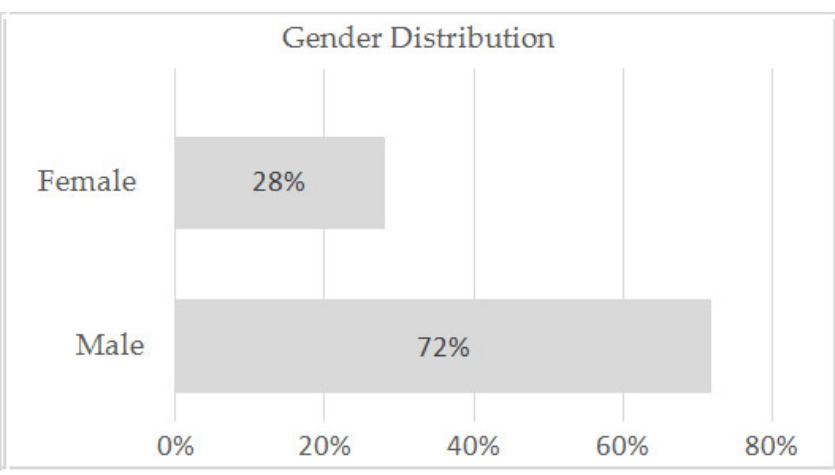

Fig. 1: Gender distribution of $n=50$

The analysis states that, their daily mean $(\bar{x})$ working hours are 8.77 that includes overtime. $100 \%$ Respondents have mentioned they don't have the overtime payment option in their organization which indicates they were staying more than 8.0 hours in order to complete their job description assigned by their organization. Along with that, their weekly mean $(\bar{x})$ working hours are 43.72 that also include overtime where an employee should work 40.00 hours per week based on "Bangladesh Labor Code 2006". Respondents daily working hours had a standard deviation of \pm 0.57 and weekly hours had a standard deviation of \pm 2.85 . However considering their regular hours (8 Hours)has a standard deviation of \pm 0 and the standard deviation came from the Respondents has a value of \pm 0.57 which has more spread compared to their regular working hours therefore their outcomes were not clustered.

The compliance of working hours is natural to be monitored by the law enforcement agencies however the off-the-book time management is also a recent issue that the employees now days encounter in the daily professional life. Besides the employee responses will be little "sarcastic" towards the question of working hour management.

Table 2: Comparison of daily and Weekly mean ( $\bar{x})$ working hours of Respondents along with the normal working hours

\begin{tabular}{|l|l|l|l|l|l|}
\hline \multicolumn{2}{|l|}{ Working hours } & \multicolumn{3}{l|}{ Working hours } \\
\hline Sl. & $\begin{array}{l}\text { Actual } \\
\text { Working } \\
\text { Hour }\end{array}$ & $\begin{array}{l}\text { Actual } \\
\text { Working } \\
\text { Hour } \\
\text { (Weekly) }\end{array}$ & Sl. & $\begin{array}{l}\text { Actual } \\
\text { Working } \\
\text { Hour }\end{array}$ & $\begin{array}{l}\text { Actual } \\
\text { Working } \\
\text { Hour } \\
\text { (Weekly) }\end{array}$ \\
\hline 1 & 9 & 45 & 26 & 10 & 50 \\
\hline 2 & 9 & 45 & 27 & 9 & 45 \\
\hline 3 & 9.5 & 45 & 28 & 8 & 40 \\
\hline 4 & 8 & 40 & 29 & 9 & 45 \\
\hline 5 & 8.5 & 40 & 30 & 8 & 40 \\
\hline 6 & 9 & 45 & 31 & 9.5 & 47.5 \\
\hline 7 & 9 & 45 & 32 & 8 & 40 \\
\hline 8 & 9 & 45 & 33 & 9 & 45 \\
\hline 9 & 8 & 40 & 34 & 8 & 40 \\
\hline 10 & 9 & 45 & 35 & 8 & 40 \\
\hline 11 & 9 & 45 & 36 & 9 & 45 \\
\hline 12 & 8 & 40 & 37 & 9 & 45 \\
\hline 13 & 9.5 & 47.5 & 38 & 9 & 45 \\
\hline 14 & 8 & 40 & 39 & 9.5 & 47.5 \\
\hline 15 & 8.5 & 42.5 & 40 & 9.5 & 47.5 \\
\hline 16 & 9 & 45 & 41 & 9 & 45 \\
\hline 17 & 9 & 45 & 42 & 8 & 40 \\
\hline 18 & 9 & 45 & 43 & 9.5 & 47.5 \\
\hline 19 & 9 & 45 & 44 & 8.5 & 42.5 \\
\hline 20 & 9 & 45 & 45 & 8 & 40 \\
\hline 21 & 8 & 40 & 46 & 9.5 & 47.5 \\
\hline 22 & 8 & 40 & 47 & 8.5 & 42.5 \\
\hline 23 & 9 & 45 & 48 & 8 & 40 \\
\hline 24 & 8.5 & 42.5 & 49 & 9.5 & 47.5 \\
\hline 25 & 9.5 & 47.5 & 50 & 9 & 45 \\
\hline & 9 & 8 & \\
\hline
\end{tabular}

*Working more than 8 hours doesn't include payment for overtime.

** Weekly working hours (40 hours/week) also include excess working hours.

Furthermore, by analyzing their workload issues it was found, $52 \%$ of Respondents were getting unwanted jobs from their supervisors which were not on their job description, and the remaining $48 \%$ has mentioned they are not getting it and this has an indication of having more workload that they were not supposed to do at their organization. Additionally, 56\% Respondents have their office mobile among them $46 \%$ of Respondents are getting calls from their organization even after finishing their working hour which indicates working overload. Also, 
office mobile is provided to reach them at any time which is a part of their organizational strategy but for the employees, it increases their workload which leads to stress.

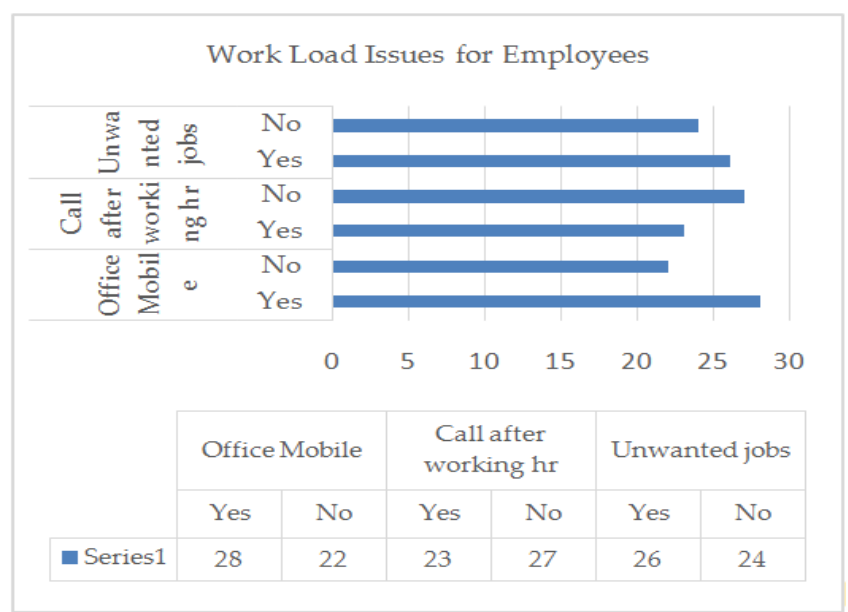

Fig. 2: Categorized workload issues for employees stating unwanted jobs given by the supervisors, getting phone calls after completing work hours and mobile phone provided to reach employees at any time

Additionally, by comparing their working hours, time spent with family, time for transportation along with a common value of 8.0 hours for their sleep. The mean ( $\bar{x})$ time spent with family is 5.37 hours and the mean $(\bar{x})$ time for transportation is 1.85 hours. Moreover, this research has also discovered that for working more than 8.0 hours Respondents are not getting any incentives for their extra work (Series refers to the responses).

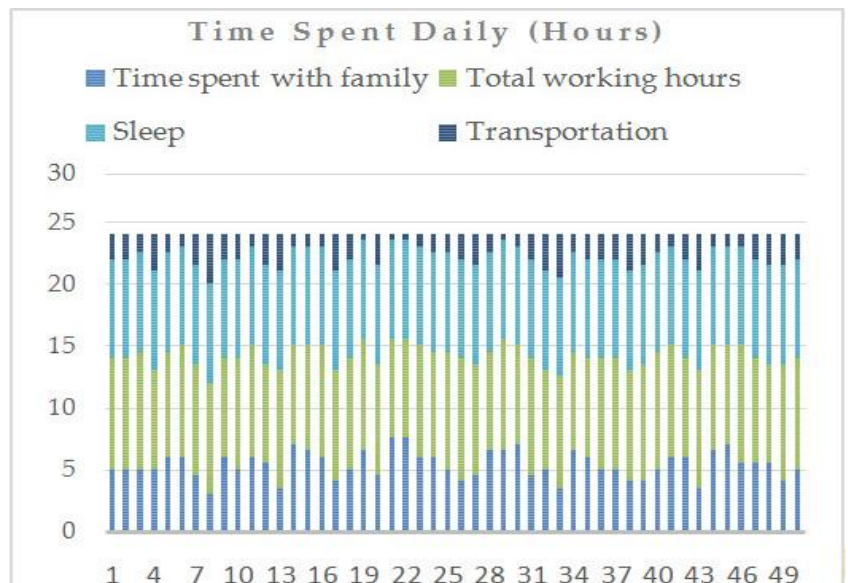

Fig. 3: The relationship between Respondents working hour, time spent with their family, the duration of sleeping and time for transportation on a day basis

Through the questionnaire it has been found that, the level of family satisfaction of Respondents where $28 \%$ of the Respondents have mentioned their family has agreed that they have satisfaction with the time they are spending with them other $18 \%$ moderately agrees that they are satisfied and the remaining $54 \%$ has mentioned that they are not satisfied with the time spent with them. Additionally, $40 \%$ of the Respondents are able to take their family outside for once in a week $42 \%$ twice in a week and rest of the $18 \%$ is able to take family outside thrice a week which also has an impact on their family dissatisfaction level. The family members were expecting some more time that should be spent with them.

However, the following findings will assist to the conclusion that the family expectations from of the employees' family barely have lateral impact on the employee responses. In some other questions on the family issues the findings will curve their present responses as the entry level employees are expected to deliver more.

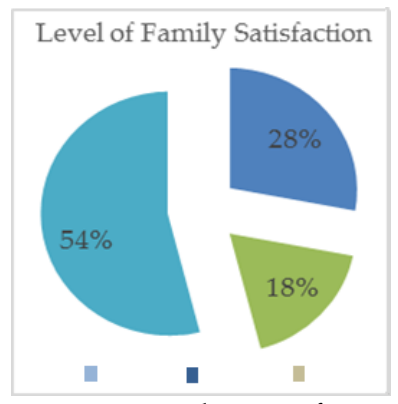

Fig. 4: Family satisfaction of the Respondents which focuses on the time spent with family members are enough or not

Table 3: Summary table of time spent with family and overall working hour of $\mathrm{n}=50$

\begin{tabular}{|l|c|c|}
\hline \multirow{2}{*}{ Summary aspects } & \multicolumn{2}{|c|}{ Findings } \\
\cline { 2 - 3 } & $\begin{array}{c}\text { Time spent } \\
\text { with family }\end{array}$ & $\begin{array}{c}\text { Overall } \\
\text { working hours }\end{array}$ \\
\hline Average & 5.37 & 8.78 \\
\hline Standard deviation & \pm 1.09 & \pm 0.57 \\
\hline Max & 7.5 & 10 \\
\hline Mean & 3 & 8 \\
\hline Mode & 5 & 9 \\
\hline
\end{tabular}

Based on this summary above it can be mentioned that the entry level employees are getting more time to spend with their families which have an average of 5.37 hours.SD for entry level employees for working hours is \pm 0.57 and the SD for time spent with family is \pm 1.09 .So there is a gap between time spent with family and overall working hour of 0.52 which indicates the demotivational factor for employees.

Additionally, the maximum time spent with family is 7.5 hours where working hour is 10 hours. Based on the mode analysis, for 50 Respondents the overall working hour is 9 and time spent with family are only 5 hours.

Table 3 has been prepared based on the facts found from the table below. And the table helped to draw a necessary conclusion in the preceding table.

To be more appropriate the following table was made to differentiate two aspects from two different dimensions time spent with family and working hours. And later on from the findings, the deliberate computation of the standard statistical treatment was made possible. 
Table 4: Comparison of time spent with family and overall working hour of $n=50$

\begin{tabular}{|c|c|c|c|c|c|}
\hline Sl. & $\begin{array}{c}\text { Time Spent } \\
\text { with Family }\end{array}$ & $\begin{array}{c}\text { Working } \\
\text { Hr. }\end{array}$ & Sl. & $\begin{array}{c}\text { Time Spent } \\
\text { with Family }\end{array}$ & $\begin{array}{c}\text { Horking } \\
\text { Hr. }\end{array}$ \\
\hline 1 & 5 & 9 & 26 & 4 & 10 \\
\hline 2 & 5 & 9 & 27 & 4.5 & 9 \\
\hline 3 & 5 & 9.5 & 28 & 6.5 & 8 \\
\hline 4 & 5 & 8 & 29 & 6.5 & 9 \\
\hline 5 & 6 & 8.5 & 30 & 7 & 8 \\
\hline 6 & 6 & 9 & 31 & 4.5 & 9.5 \\
\hline 7 & 4.5 & 9 & 32 & 5 & 8 \\
\hline 8 & 3 & 9 & 33 & 3.5 & 9 \\
\hline 9 & 6 & 8 & 34 & 6.5 & 8 \\
\hline 10 & 5 & 9 & 35 & 6 & 8 \\
\hline 11 & 6 & 9 & 36 & 5 & 9 \\
\hline 12 & 5.5 & 8 & 37 & 5 & 9 \\
\hline 13 & 3.5 & 9.5 & 38 & 4 & 9 \\
\hline 14 & 7 & 8 & 39 & 4 & 9.5 \\
\hline 15 & 6.5 & 8.5 & 40 & 5 & 9.5 \\
\hline 16 & 6 & 9 & 41 & 6 & 9 \\
\hline 17 & 4 & 9 & 42 & 6 & 8 \\
\hline 18 & 5 & 9 & 43 & 3.5 & 9.5 \\
\hline 19 & 6.5 & 9 & 44 & 6.5 & 8.5 \\
\hline 20 & 4.5 & 9 & 45 & 7 & 8 \\
\hline 21 & 7.5 & 8 & 46 & 5.5 & 9.5 \\
\hline 22 & 7.5 & 8 & 47 & 5.5 & 8.5 \\
\hline 23 & 6 & 9 & 48 & 5.5 & 8 \\
\hline 24 & 6 & 8.5 & 49 & 4 & 9.5 \\
\hline 25 & 5 & 9.5 & 50 & 5 & 9 \\
\hline
\end{tabular}

The outcome of the overall level of job satisfaction was negative. $54 \%$ of the Respondents has mentioned that they are not satisfied with their job the remaining $46 \%$ has the job satisfaction even though they are facing work-related problems at their organization.

The responses are variable however is showing a central tendency towards the conclusive statements. The dissatisfaction rate may indicate towards their dissatisfaction regarding following issues, such as, Overtime Payment, Job Sharing Opportunities, the desired work or the type of works is bestowed upon them, etc. which the management can manipulate any time at will.

Essentially the response is dependent on the respondents' at home experience based on the reactions they receive from family members.

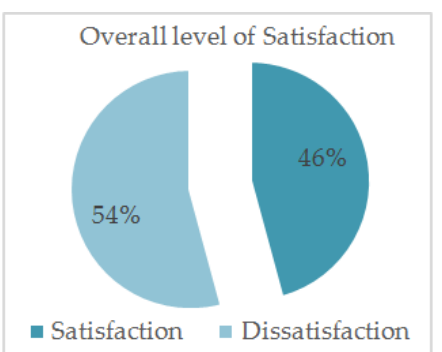

Fig. 5: Job satisfaction of the Respondents

The reason behind job dissatisfaction in regard to worklife balance impacts from family members. Most of them are not satisfied with the time spent with them and also employees are not able to take them outside for social program which seems unsocial for them.

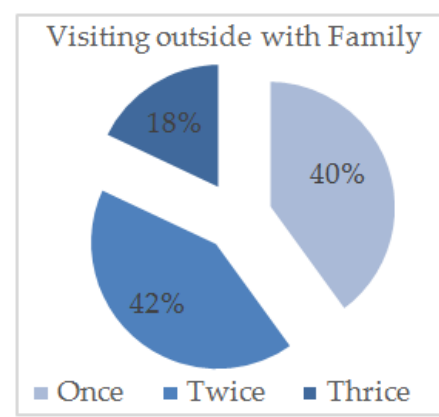

Fig. 6: Visiting outside with family on a weekly basis

\section{MAJOR FINDINGS}

Through the analysis discussed above, it has been found that the Work-Life imbalance issue is raised due to working more than regular working hours without any payment for overtime. On the other hand, working for more than 8.0 hours leads them to spend less time with their family members, and that is considered as a demotivating factor for the employees. The work-life issue arises when an individual is not able to balance work and life. Through this research, it has been found that $54 \%$ of the Respondents are not satisfied with their organization for that above reason.

Nevertheless employees also gets de-motivated when they get unwanted tasks from their supervisors because they are not getting any extra payment or motivation for doing those tasks that are not included in their job description which indicates employees are more concerned in working according to their job description. Additionally getting calls from the organization during weekend also negatively impact employees since they are on holiday. Working during holidays is very much unexpected for them as because every employee has their personal life and they also have some plans on weekend with their family. In such case, getting calls from the organization really disrupts their plans as well as their mental peace of going somewhere with his/her family member. Additionally, 36\% married employees may not satisfied with extra jobs and or working hours as because they have to spend some time with his/her spouse which also triggers imbalanced work-life.

There is a possibility of switching, but the factor is, availability of jobs. As a result employees are reluctant to switch. On the other hand, job security is also a key issue for Bangladeshi employees. Because any action of employees may lead immediate termination for the employee with or without notice. As a result, staffs are becoming exhausted.

A legitimate work-life balance creates a healthy employment practice and creates more committed employees for the organization, and that certainly works as an intrinsic reward 
for the employees. If an organization can succeed providing a better work-life balance opportunity for its employees it will be a better investment for the organization. The data analysis shows the real picture of unbiased response, whilst verbal and casual topic for discussion shows excessive dissatisfaction for the employees. And that is when the development of professionalism comes under consideration. The development of professionalism entitles few steps including, training, proper socialization, providing proper guidelines to the employees and train them to be patient and finally feedback. These features will also ensure the future employee commitment and will contribute to their future productivity.

However, if the scenario changes oppositely that the mid-level and the top-level personnel are fighting with this work-life balance issue the HR has some steps sketched out to solve them; Such as, Flexible working time (period), Training and development, Shared or distributed leadership, Pay rise, Childcare support, Occupational therapy etc. (Nwagbara et al. 2012).

\section{CONCLUSION}

The reason for conducting this research was to find the reason behind having imbalance in work and life. In broader sense employees are not getting job satisfaction at the workplace. Moreover inconsistent Work-Life balance creates an adverse impact while developing professionalism and job insecurity discourages employees not to work with their utmost concentration which ultimately reduces their productivity level at work. Indeed this factor is not favoring creating professionalism in Bangladesh rather it has negative impact on employees for their working environment. It also creates a negative impact on the organization as the employees are not getting any motivation for working.

It seems to be impossible to keep everyone on the same page where satisfying everyone is not at all concern for the corporations. The companies should be considerate in many other ways through which positive changes may be brought. However, it is undeniable that the employees should also be patient, concerned and also be open enough to broadcast their opinions to the organization.

\section{REFERENCE}

Baral, R. Bhargava, S. 2011. Predictors of work-family enrichment: moderating effect of core self-evaluations. Journal of Indian Business Research, 3(4): 220-243.

Boswell, W., Julie O. B. 2007. "The Use of Communication Technologies after Hours: The Role of Work Attitudes and Work-Life Conflict." Journal of Management 33.4: 592-608.
Clark, S. C. (2000). Work/family border theory: A new theory of work/family balance. Human Relations, 53, 747-770.

Dhas, D. B., Karthikeyan, P. 2015. “Work-Life Balance Challenges and Solutions: Overview". International Journal of Research in Humanities and Social Studies. 2(12): 10-19

Drew, E., \& Murtagh, E. M. 2005. Work-life balance: senior management champions or laggards? Women in Management Review, 20(4): 262-278.

Eikhof, D. R., Warhurst, C., \& Haunschild, A. 2007. Introduction: What work? What life? What balance? Critical reflection on the work-life balance debate. Employee Relation, 29(4): 325-333.

Estes, S. B., \& Michael, J. 2005. Work-family policies and gender inequality at work: A Sloan Work and Family Encyclopedia entry. Retrieved March 16, 2016, from http:/ / wfnetwork.bc.edu/encyclopedia_entry.php?id=1230\& area $=$ All

Greenhaus, J. H., Collins, K. M., Shaw, J. D. 2003. The relation between work-family balance and quality of life. Journal of Vocational Behavior, 63: 510-531.

Hobson, C.J., L. Delunas and D. Kesic. 2001. Compelling evidence of the need for corporate work/life balance initiatives: results from a national survey of stressful life events. Journal of Employment Counseling 38(1): 38-44.

Hudson. 2005. The Case for Work/Life Balance: Closing the Gap between Policy and Practice. Retrieved May 10, 2016, from http:/ /au.hudson.com/Portals/AU/documents/Hudson2 020_Work-Life.pdf

Kar, S., \& Misra, K. 2013. Nexus between Work Life Balance Practices and Employee Retention - The Mediating Effect of a Supportive Culture. Asian Social Science, 9, 63-69.

Kirchmeyer, C. 2000. Work-life initiatives: Greed or benevolence regarding workers time. In C. L.v Cooper \& D. M. Rousseau (Eds.), Trends in organizational behavior (Vol. 7, pp. 79-93). West Sussex, UK: Wiley.

Kofodimos, J. R. 1990. Why executives lose their balance. Organizational Dynamics, 19 (1), 58-73.

Marks, S. R., \& MacDermid, S. M. (1996). Multiple roles and the self: A theory of role balance. Journal of Marriage and the Family, 58, 417-432.

Nawaz, M. T., Zaman, K. F. 2012. Work-Life balance: Is still a new concept in private commercial banking sector of Bangladesh? International Journal of Research Studies in Management, 2: 57-66.

Nwagbara, U., Akanji, B. O. 2012. “The Impact of Work-Life Balancee on the Commitment and Motivation of Nigerian Women Employees". International Journal of Academic Research in Business \& Social Sciences. 2: 39-47.

Susi, S., \& Jawaharrani, K. 2011. Work-Life Balance: The key driver of employee engagement. Asian Journal of Management Research, 2(1), 474-483.

$--0--$

Online Archive: $\underline{\text { http://journals.abc.us.org/index.php/abr/issue/archive }}$

\section{5f) Worldcat Google scholar

